\title{
The toxicity of neem (Azadirachta indica), citronella (Cymbopogon nardus), castor (Ricinus communis), and clove (Syzygium aromaticum) oil against Spodoptera frugiperda
}

\author{
Danar Dono ${ }^{1-2^{*}}$, Yusup Hidayat ${ }^{1-2}$, Tarkus Suganda ${ }^{2}$, Syarif Hidayat ${ }^{2}$, Neneng Sri Widayani ${ }^{3}$ \\ ${ }^{1}$ Centre for Product Development and Partnership Study (Puspromit), West Java, Indonesia 45363 \\ ${ }^{2}$ Department of Plant Pests and Diseases, Agriculture Faculty, Universitas Padjadjaran, West Java, Indonesia 45363 \\ ${ }^{3}$ Alumny of Study Program of Agronomy, Agriculture Faculty, Universitas Padjadjaran \\ *Corresponding Author: danar.dono@unpad.ac.id
}

Received June 26, 2020; revised June 26, 2020; accepted June 30, 2020

\begin{abstract}
Major or key pest in corn plantation recently reported in Indonesia was Spodoptera frugiperda, a polyphagous pest that have a fast spread rate and caused high damage on young corn. One of pest control that able to use is botanical insecticide. The experiment begins with a screening test of neem, jatropha, clove, and citronella oil, and then continued with bioassay of the botanicals oil that cause higher mortality to test insect. Every kind of botanicals oils tested at concentrations of $0.1 \%$ and $0.05 \%$ against $S$. frugiperda. Tests carried out using the feeding assay or residue on corn leaves (size $5 \times 5 \mathrm{~cm}$ ). Then, the leaf treatment was given to 10 larvae of S. frugiperda (instars 2) for 48 hours. After that, the leaf replaced with untreated baby corn as feed until the larvae develop to pupa. The control leaves only treated with aquades contain mixture of emulsifier Tween 80 and Span 80 (ratio 4:1) at concentration of $0,5 \%$. The kind of botanical oil that caused the highest mortality of the test insect larvae was further bioassay to determine the relationship of concentration with test insect mortality. The testing was carried out using a series of concentrations which resulted in the death of test insects between 0 $<\mathrm{x}<100 \%$. The test results showed that concentration neem oil of $0.1 \%$ caused the highest mortality of S. frugiperda. Neem oil exposure is also able to inhibit the time of larval development, reduce the percentage of feed consumption, and the weight of pupa the $S$. frugiperda. Other vegetable oils exposure gave lower mortality in the test insects and some treatments were not significantly different from the controls on the parameters of larval development, pupae weight, and percentage of feed consumption. Neem oils showed strong toxicity against $S$. frugiperda larvae with Lethal Concentration $50\left(\mathrm{LC}_{50}\right)$ of $0.08 \%$ and $\mathrm{LC}_{95}$ of $0.34 \%$.
\end{abstract}

Keywords: Botanical Insecticide,Toxicity, New Invasive

\begin{abstract}
ABSTRAK
Toksisitas Minyak Mimba (Azadirachta indica), serai wangi (Cymbopogon nardus), jarak (Ricinus communis), dan cengkeh (Syzygium aromaticum) terhadap S. frugiperda
\end{abstract}

Hama penting pada tanaman jagung yang baru-baru ini dilaporkan serangannya di Indonesia adalah Spodoptera frugiperda. Hama polifagus ini memiliki tingkat penyebaran yang cepat dan dapat mengakibatkan kerusakan yang tinggi pada tanaman jagung muda. Salah satu pengendalian hama yang dapat dikembangkan yaitu menggunakan insektisida nabati. Pengujian diawali dengan uji penapisan minyak mimba, jarak, cengkeh, dan serai wangi, kemudian pengujian dilanjutkan dengan uji hayati minyak nabati yang mengakibatkan kematian serangga uji tertinggi. Pengujian penapisan setiap jenis minyak nabati dilakukan pada konsentrasi $0,1 \%$ dan $0,05 \%$ terhadap larva S. frugiperda. Pengujian dilakukan menggunakan metode residu pada daun jagung berukuran 5 x $5 \mathrm{~cm}$. Daun perlakuan selanjutnya diberikan pada 40 ekor larva $S$. frugiperda instar dua (10 larva per petri, diameter $9 \mathrm{~cm}$ ) selama 48 jam dan selanjutnya daun pakan diganti dengan jagung semi (baby corn) pakan tanpa perlakuan hingga larva berkembang menjadi pupa. Daun pakan perlakuan kontrol hanya diberi campuran larutan akuades dan pengemulsi 0,5\% (campuran tween 80 dan Span $80=4: 1$ ). Jenis minyak nabati yang mengakibatkan kematian tertinggi terhadap larva uji selanjutnya diuji lebih lanjut untuk menentukan hubungan konsentrasi dengan kematian serangga uji. Pengujian dilakukan menggunakan satu seri konsentrasi yang mengakibatkan kematian serangga uji antara $0<\mathrm{x}<$ $100 \%$. Hasil pengujian menunjukkan bahwa minyak mimba konsentrasi $0.1 \%$ menyebabkan kematian tertinggi terhadap $S$. frugiperda dibanding minyak nabati lainnya. Selain itu, minyak mimba juga memperpanjang lama waktu perkembangan larva, serta menurunkan persentase konsumsi pakan, dan bobot pupa S. frugiperda. Minyak biji mimba memiliki toksisitas yang kuat terhadap larva $S$. frugiperda dengan nilai $\mathrm{LC}_{50} 0,08 \%$ dan $\mathrm{LC}_{95} 0,34 \%$..

Keywords: Insektisida botani, Toksisitas, Hama baru invasif

\section{PENDAHULUAN}

Kehadiran Organisme Pengganggu Tanaman (OPT) menjadi salah satu faktor utama yang dapat menurunkan produktivitas tanaman. Salah satu hama penting pada tanaman jagung yang baru-baru ini dilaporkan keberadaannya di Indonesia adalah Spodoptera frugiperda (Maharani et al, 2019; Trisyono et al., 2019). S. frugiperda atau biasa disebut Fall Armyworm (FAW) adalah serangga asli daerah tropis dan subtropis di Amerika (Goergen et al., 
2016). S. frugiperda pertama kali terdeteksi di Indonesia di Sumatra Barat pada bulan Maret 2019, dan dalam waktu 4 bulan hama telah pindah ke 12 provinsi di Indonesia di Sumatra, Jawa dan beberapa bagian di Kalimantan (FAO, 2019). Kecepatan penyebaran hama ini mungkin disebabkan karena $S$. frugiperda mampu memiliki beberapa generasi per tahun dan ngengat dapat terbang hingga $1600 \mathrm{~km}$ dalam 30 hari (53,3 km per hari) (Johnson, 1987).

S. frugiperda diketahui menyerang lebih dari 100 tanaman, namun kerusakan terbesar adalah serangan pada jagung, padi, sorgum, dan tanaman tebu (Abrahams et al., 2017). Adapun kehilangan hasil pada tanaman jagung akibat serangan hama ini mencapai 34\% (Dequech et al. 2007). Bahkan menurut laporan Trisyono et al., (2019), larva merusak jagung muda dengan kerusakan mencapai $100 \%$. Kerusakan yang ditimbulkan cukup besar karena larva $S$. frugiperda memakan daun jagung muda yang dapat menyebabkan kehilangan hasil yang cukup tinggi (De Almeida et al., 2002). Spesies ulat grayak ini memiliki tingkat keperidian yang tinggi dan kerakusan makan hingga 10 kali dibandingkan dengan Spodoptera litura dan Spodoptera exigua (Sukamto 2019). Oleh karena itu, kehadiran hama ini harus segera dikendalikan dengan tepat agar tidak menyebabkan kerugian hasil yang signifikan pada tanaman jagung. Salah satu teknik pengendalian yang dapat dilakukan adalah menggunakan insektisida nabati.

Indonesia memiliki keragaman tumbuhan yang tinggi yang potensial untuk dikembangkan sebagai sarana pengendalian hama atau yang dikenal dengan insektisida nabati. Insektisida nabati dari berbagai tumbuhan telah diketahui memiliki metabolit sekunder yang memiliki aktivitas insektisida terhadap serangga (Arivoli \& Tennyson, 2013; Koul, 2008; Paul \& Sohkhlet, 2012; Syahputra et al., 2006; Syahputra et al. 2019; Zapata, Budia, Viñuela, \& Medina, 2009). Sebagai contoh tumbuhan yang memiliki sifat insektisida diantaranya mimba (Azadirachta indica), serai wangi (Cymbopogon nardus), jarak (Ricinus communis), dan cengkeh (Syzygium aromaticum). Ekstraksi bahan pestisida dari keempat tumbuhan tersebut dapat menghasilkan minyak yang dapat digunakan sebagai sarana pengendalian hama. Berdasarkan studi literature, mimba memiliki kandungan azadirakhtin yang bekerja dengan mekanisme kerja sebagai penolak makan (repellent), menghambat pertumbuhan dan akhirnya mematikan serangga (Samsudin, 2011). Minyak serai wangi dengan kandungan citronella memiliki sifat repellent dan antifeedan (Rohimatun \& Laba, 2013). Ekstrak daun cengkeh efektif sebagai repellent terhadap Musca dosemtica (Aliah et al., 2016). Adapun minyak biji jarak dapat mematikan larva Aedes aegypti pada konsentrasi 116,26 ppm $(0,0116 \%)$ sebesar $90 \%$ (Wamaket et al., 2018) dan pada konsentrasi 2,5\% mengakibatkan kematian larva Spodoptera littoralis sebesar 90\% (Bakr et al., 2015)
Namun keempat jenis ekstrak tanaman tersebut belum diuji terhadap $S$. frugiperda. Oleh karena itu pada penelitian ini dilakukan penapisan toksisitas minyak mimba, jarak, cengkeh, dan serai wangi terhadap larva S. frugiperda. Dari hasil uji tapis, jenis minyak nabati yang mengakibatkan kematian serangga uji tertinggi diuji lebih lanjut untuk mengetahui hubungan konsentrasi dengan kematian serangga uji

\section{METODE}

\section{Persiapan percobaan}

S. frugiperda yang digunakan merupakan serangga yang dikumpulkan dari lahan pertanaman jagung di Desa Cileles, Kabupaten Sumedang. Selanjutnya larva $S$. frugiperda diperbanyak di ruang perbanyakan serangga Departemen Hama dan Penyakit Tanaman, Fakultas Pertanian, Universitas Padjadjaran. Generasi ke-dua dan selanjutnya digunakan untuk pengujian. Pakan serangga uji menggunakan daun bagian tengah tanaman jagung berumur sekitar satu bulan. Lama pemberian pakan daun berperlakuan kepada larva serangga uji yaitu $2 \times 24$ jam dan pada hari selanjutnya daun pakan diganti menggunakan buah jagung semi (baby corn).

Minyak nabati yang digunakan sebagai insektisida nabati berasal dari minyak biji mimba (Azadirachta indica), minyak biji jarak (Ricinus communis), minyak serai (Cymbopogon nardus), dan minyak cengkeh (Syzygium aromaticum) yang dilarutkan dalam akuades yang mengandung pengemulsi. Pengemulsi yang digunakan yaitu tween $80+$ span 80 dengan perbandingan 4:1 pada konsentrasi $0,5 \%$.

\section{Pelaksanaan percobaan}

\section{Uji Penapisan}

Pengujian skrening toksisitas dilakukan menggunakan metode residu pada pakan (daun jagung berukuran 5 x $5 \mathrm{~cm}$ ). Rancangan uji menggunakan Rancangan Acak Kelompok (RAK) yang terdiri dari perlakuan minyak biji mimba, minyak serai, minyak biji jarak, dan minyak cengkeh pada konsentrasi uji $0,05 \%$ dan $0,1 \%$ yang diulang empat kali. Daun jagung dicelupkan pada larutan insektisida berdasarkan perlakuan selama 20 detik kemudian dikering anginkan. Daun pakan berperlakuan dimasukkan ke dalam cawan petri, kemudian ke dalam cawan petri tersebut dimasukkan 10 serangga uji instar 2 menggunakan kwas halus no 3. Setelah 48 jam pemaparan, pakan diganti dengan potongan jagung semi tanpa perlakuan. Selain pergantian pakan, setelah 48 jam setelah pemaparan, masing-masing serangga uji dipisahkan dalam cup plastik masingmasing satu larva per cup plastik untuk menghindari kematian serangga uji akibat sifat kanibalisme dari $S$. frugiperda.

Peubah yang diamati yaitu kematian serangga uji, lama perkembangan serangga uji yang 
bertahan hidup, luas konsumsi daun pakan perlakuan, dan bobot pupa. Pengamatan kematian larva dilakukan dengan menghitung jumlah larva yang mati hingga larva mencapai instar 6. Pengamatan kematian larva dilakukan setiap hari dengan jangka waktu 24 jam. Persentase kematian dihitung berdasarkan:

$$
\text { Persentase kematian }(\%)=\frac{\Sigma \text { larva mati }}{\Sigma \text { larva uji }} \times 100 \%
$$

Lama perkembangan larva diamati dengan mencatat waktu yang diperlukan larva $S$. frugiperda untuk berkembang dari instar tertentu ke instar berikutnya yang ditandai dengan pergantian kutikula larva. Pengamatan dilakukan setiap hari dengan jangka waktu 24 jam. Pengamatan bobot pupa dilakukan dengan menimbang bobot pupa $S$. frugiperda menggunakan timbangan analitik.

Pengamatan konsumsi pakan dilakukan dengan mengukur luas area yang dimakan oleh larva kemudian disalin di atas kertas milimeter blok. Bagian yang berlubang diarsir dengan menggunakan pensil 2B Kemudian, luas area yang makan dihitung sebegai persentase menggunakan persamaan:

Konsumsi pakan $(\%)=\frac{\Sigma \text { luas daun yang dimakan }}{\Sigma \text { total luas daun }} \times 100 \%$

Data mortalitas, lama perkembangan, bobot larva dan konsumsi pakan dianalisis menggunakan program SPSS versi 25.

\section{Uji Toksisitas}

Jenis minyak nabati yang mengakibatkan kematian tertinggi terhadap larva uji, S. frugiperda, selanjutnya diuji lebih lanjut untuk menentukan toksisitas relatifnya yaitu melalui studi hubungan konsentrasi dengan kematian serangga uji. Pengujian dilakukan menggunakan satu seri konsentrasi yang mengakibatkan kematian serangga uji antara $0<\mathrm{x}<$ $100 \%$. Seri konsentrasi ditentukan berdasarkan uji pendahuluan dan uji lanjutan. Cara perlakuan minyak nabati dilakukan dengan cara yang sama dengan percobaan uji penapisan.

Peubah yang diamati yaitu kematian serangga uji akibat perlakuan berbagai konsentreasi minyak nabati. Hubungan konsentrasi dengan mortalitas serangga uji dianalisis menggunakan analisi probit (Finney, 1971).

\section{HASIL DAN PEMBAHASAN}

Hasil uji toksistas empat minyak nabati menunjukkan bahwa minyak mimba konsentrasi $0,1 \%$ menyebabkan kematian tertinggi terhadap $S$. frugiperda yaitu 42,5\%. Adapun kematian $S$. frugiperda lainnya pada perlakuan minyak jarak konsentrasi $0,1 \%$; minyak cengkeh $0,1 \%$, dan minyak serai $0,1 \%$ menyebabkan kematian berturut-turut
27,5\%; 25\%; dan 25\%. Selanjutnya pada konsentrasi yang lebih rendah yaitu $0,05 \%$ kematian $S$. frugiperda akibat paparan minyak jarak, cengkeh, serai dan mimba yaitu $12,5 \% ; 15 \% ; 12,5 \%$; dan $22,5 \%$. Terlihat bahwa paparan akibat minyak mimba masih menyebabkan kematian tertinggi dibandingkan paparan insektisida dari minyak lainnya (Tabel 1). Kematian serangga uji disebabkan adanya kandungan senyawa insektisida pada minyak yang digunakan.

Seperti hasil peneltian lainnya yang menunjukkan bahwa keempat minyak nabati tersebut mampu mematikan serangga uji. Hasil penelitian tersebut antara lain, pada konsentrasi $1 \%$ minyak serai dapat mematikan $82 \%$ ulat bulu gempinis (Ganjawela, 2009). Labinas \& Crocomo (2002) melaporkan bahwa minyak serai dari spesies $C$. winterianus pada konsentrasi $0,5 \%$ yang diaplikasikan dengan cara penyemprotan pada permukaan cawan petri dapat mengakibatkan kematian S. frugiperda. mendekati $100 \%$. Hasil pengujian Pinheiro et al. (2013) menunjukkan bahwa minyak serai memiliki $\mathrm{LC}_{50}$ 0,36\% (Sk95\% 0,30 - 0,41\%) dan $\mathrm{LC}_{90} 0,66 \%$ (SK 95\% 0,57-0,81\%) terhadap Mizus persicae.

Minyak biji jarak dapat mempersingkat waktu perkembangan larva, pupa dan menekan pembentukan dan bobot pupa, serta memiliki nilal $\mathrm{LC}_{90}$ sebesar 2,5\% terhadap Spodoptera littoralis (Bakr et al., 2015). Perlakuan fraksi diklorometana ekstrak biji jarak pada konsentrasi 10\% mampu mematikan Crocidolomia binotalis sebesar 73,8\% (Pebriansyah et al., 2016), dan pada konsentrasi 10\% mampu mamatikan $100 \%$ Plutella xylostella (Kodjo et al., 2011). Pemberian minyak cengkeh konsentrasi $10 \%$ dapat mematikan $100 \%$ ulat bulu gempinis (dari family Lymantriidae, Arctiidae dan Lymacodidae), pada konsentrasi $0,9 \%$ dapat mematikan $50 \%$ Aedes albopictus, dan pada konsentrasi $1 \%$ - $5 \%$ menyebabkan kematian $12,5 \%$ hingga $87,9 \%$ Oryctes Agamemnon (Astuthi et al., 2012; Puji et al., 2011; Ibrahim \& Alahmadi, 2015). Dapat dilihat bahwa konsentrasi yang berbeda dibutuhkan untuk mematikan serangga uji yang berbeda.

Adapun pada penelitian ini kematian serangga uji masih rendah sehingga konsentrasi minyak nabati yang digunakan perlu ditingkatkan, mengingat bahwa konsentrasi uji yang digunakan masih dalam batas konsentrasi yang layak digunakan $(0,05$ dan $0,1 \%)$. Berdasarkan hasil uji skrining tersebut diketahui bahwa kematian $S$. frugiperda tertinggi diakibatkan oleh perlakuan minyak mimba, sehingga minyak mimba dipilih untuk diuji lebih lanjut agar diketahui toksisitas relatif minyak mimba terhadap $S$. frugiperda. Persentase konsumsi pakan yang diberi paparan minyak mimba, cengeh, jarak, dan serai lebih rendah dari kontrol namun berbedasarkan uji statistik tidak berbeda nyata dengan kontrol kecuali perlakuan minyak mimba konsentrasi $0,1 \%$. 


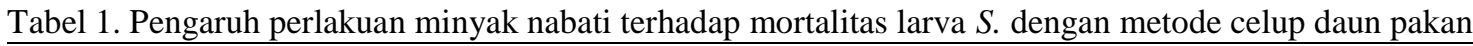

\begin{tabular}{|c|c|c|c|c|c|c|c|}
\hline \multirow{2}{*}{ Perlakuan } & \multicolumn{7}{|c|}{ Mortalitas S. frugiperda pada (HSP) (\%) } \\
\hline & 2 & 4 & 6 & 8 & 10 & 12 & 14 \\
\hline Jarak $(0,05 \%)$ & $5,0 \mathrm{ab}$ & $12,5 \mathrm{ab}$ & $12,5 \mathrm{ab}$ & $12,5 \mathrm{ab}$ & $12,5 \mathrm{ab}$ & $12,5 \mathrm{ab}$ & $12,5 \mathrm{ab}$ \\
\hline Jarak $(0,1 \%)$ & $10,0 \mathrm{ab}$ & $27,5 \mathrm{~cd}$ & $27,5 \mathrm{bc}$ & $27,5 \mathrm{c}$ & $27,5 \mathrm{c}$ & $27,5 \mathrm{c}$ & $27,5 \mathrm{c}$ \\
\hline Cengkeh $(0,05 \%)$ & $5,0 \mathrm{ab}$ & $15,0 \mathrm{bc}$ & $15,0 \mathrm{bc}$ & $15,0 \mathrm{bc}$ & $15,0 \mathrm{bc}$ & $15,0 \mathrm{bc}$ & $15 \mathrm{bc}$ \\
\hline Cengkeh $(0,1 \%)$ & $10,0 \mathrm{ab}$ & $25,0 \mathrm{bcd}$ & $25,0 \mathrm{bc}$ & $25,0 \mathrm{bc}$ & $25,0 \mathrm{bc}$ & $25,0 \mathrm{bc}$ & $25 \mathrm{bc}$ \\
\hline Serai $(0,05 \%)$ & $5,0 \mathrm{ab}$ & $12,5 \mathrm{bcd}$ & $12,5 \mathrm{ab}$ & $12,5 \mathrm{ab}$ & $12,5 \mathrm{ab}$ & $12,5 \mathrm{ab}$ & $12,5 \mathrm{ab}$ \\
\hline Serai $(0,1 \%)$ & $5,0 \mathrm{ab}$ & $22,5 \mathrm{ab}$ & $25,0 \mathrm{bc}$ & $25,0 \mathrm{bc}$ & $25,0 \mathrm{bc}$ & $25,0 \mathrm{bc}$ & $25 \mathrm{bc}$ \\
\hline $\operatorname{Mimba}(0,05 \%)$ & $12,5 \mathrm{~b}$ & $20,0 \mathrm{bcd}$ & $22,5 \mathrm{bc}$ & $22,5 \mathrm{bc}$ & $22,5 \mathrm{bc}$ & $22,5 \mathrm{bc}$ & $22,5 b c$ \\
\hline $\operatorname{Mimba}(0,1 \%)$ & $12,5 \mathrm{~b}$ & $32,5 \mathrm{~d}$ & $40,0 \quad d$ & $42,5 \mathrm{~d}$ & $42,5 \mathrm{~d}$ & $42,5 \mathrm{~d}$ & $42,5 \mathrm{~d}$ \\
\hline Kontrol & 0,0 a & $0,0 \quad \mathrm{a}$ & $0,0 \mathrm{a}$ & $0,0 \quad \mathrm{a}$ & $0,0 \mathrm{a}$ & $0,0 \quad \mathrm{a}$ & $0,0 \mathrm{a}$ \\
\hline
\end{tabular}

Keterangan : Angka yang diikuti huruf yang sama pada setiap kolom tidak berbeda nyata menurut uji Duncan pada taraf nyata $5 \%$. HSP : Hari Setelah Perlakuan

Pada Tabel 2 disajikan rata-rata persentase konsumsi pakan $S$. frugiperda pada perlakuan minya jarak dan cengkeh adalah 20,97\%; 24,26\%, pada perlakuan serai luas konsumsi pakan $17,60 \% ; 20,77$ $\%$ dan pada perlakuan minyak mimba $13,27 \%$ dan $14,28 \%$ pada konsentrasi $0,1 \%$ dan $0,05 \%$. Jika diurutkan maka, minyak mimba merupakan perlakuan yang memberikan anti makan paling tinggi diikuti oleh serai wangi terhadap aktivitas makan $S$. frugiperda setelah paparan minyak tersebut (Tabel 2). Hal ini sejalan dengan beberapa hasil penelitian bahwa bahwa minyak mimba memiliki aktivitas anti makan bagi serangga (Senthil-Nathan, 2013; Shannag et al., 2015).

Persentasi konsumsi pakan dipengaruhi oleh banyaknya aktivitas makan larva $S$. frugiperda. Aktivitas makan tersebut dipengaruhi oleh sifat repellent dan antifeedant yang diberikan minyak nabati sehingga menjauh dari pakan dan mengurangi konsumsi pakan. Diketahui bahwa cengkeh efektif sebagai repellent (Aliah dkk., 2016; Faheem \& Abduraheem, 2019). Serai wangi memiliki sifat repellent dan antifeedan (Rohimatun \& Laba, 2013; Manurung dkk., 2013; (Hernandez-Lambrano, 2015). Serta mimba yang memberikan sifat repellent serta efek primer berupa antifeedant yang mengganggu persepsi rangsangan untuk makan (phagostimulant) (Ahadian, 2012; Faheem \& Abduraheem, 2019).

Pengamatan lama perkembangan dilakukan untuk mengetahui pengaruh minyak nabati yang diujikan terhadap lama perkembangan larva atau dari suatu instar ke instar berikutnya. Pada Tabel 3 disajikan bahwa pada paparan minyak jarak konsentrasi $0,1 \%$ dan $0,5 \%$, lama perkembangan larva dari instar II-III; II-IV; II-V; II-VI berturut-turut 2,35 hari; 4,57 hari; 7,40 hari; 10,43 serta 2,75 hari; 4,72 hari; 7,93 hari; 1,76 hari. Adapun pada perlakuan lainnya diketahui bahwa lama perkembangan larva yang paling lama adalah pada perlakuan insektisida mimba $0,1 \%$ dimana lama perkembangan dari instar
II-V dan II-VI adalah 11,17 hari dan 13,30 hari. Sedangkan pada kontrol lama perkembangan dari instar II-VI adalah 10,57 hari. Kemudian pada perlakuan lainnya yaitu minyak cengkeh dan serai wangi, lama perkembangan larva tidak jauh berbeda dengan perlakuan minyak jarak dan kontrol dimana lama perkembangan larva dari instar II-VI adalah sekitar 10 hari (Tabel 3).

Penghambatan perkembangan larva akibat perlakuan ekstrak tumbuhan juga dilaporkan pada beberapa hasil penelitian yang telah dilakukan sebelumnya. Pengujian ekstrak etanol biji jarak (2239 ppm) terhadap Spodoptera littoralis larva instar 2 menghambat perkembangan larva menjadi 17,08 hari sedangkan pada kontrol 15,58 hari (Bakr et al., 2015). Hambatan perkembangan tersebut disebabkan karena inhibitor trypsin pada minyak jarak mampu mengurangi penyerapan residu asam amino esensial oleh serangga sehingga mengganggu perkembangan S. frugiperda (Ramos et al., 2013). Senyawa aktif dari minyak cengkeh dapat menyebabkan peningkatan amilase pada Tribolium castanem melalui beberapa aktivitas fisiologis, sehingga menghambat perkembangan hingga menyebabkan kematian serangga (Ajayi et al., 2018; Mishra et al., 2016).

Hasil pengamatan terhadap bobot pupa $S$. frugiperda setelah paparan minyak mimba, jarak, cengkeh, dan serai wangi menunjukkan tidak berbeda nyata antar perlakuan. Namun jika dibandingkan dengan kontrol, perlakuan minyak cengkeh $0,1 \%$ dan minyak mimba $0,1 \%$ berbeda nyata. Bobot pupa pada kontrol rata-rata mencapai $0,2213 \mathrm{~g}$, sedangkan pada perlakuan minyak jarak $0,05 \%$ dan $0,1 \%$ bobot pupa $0,2202 \mathrm{~g}$ dan 0,2239 g lebih besar dibanding kontrol, namun secara statistik tidak berbeda nyata dengan kontrol.

Adapun pada perlakuan lainnya, bobot pupa lebih rendah dibandingkan kontrol dengan bobot paling rendah pada perlakuan minyak cengkeh $0,1 \%$ dan minyak mimba $0,1 \%$ dengan bobot pupa $0,1866 \mathrm{~g}$ 
dan 0,1829 g (Tabel 4). Bobot yang rendah diduga efek antifeedant yang terdapat pada minyak mimba sehingga aktivitas makan terhambat dan laju konsumsi menurun (Widayani dkk., 2018). Penurunan konsumsi pakan akan berdampak pada bobot serangga (Mardiningsih dkk., 2010).

Tabel 2. Pengaruh perlakuan minyak nabati terhadap konsumsi pakan S. frugiperda

Perlakuan

\begin{tabular}{ll}
\hline Jarak $(0,05 \%)$ & $20,97 \pm 5,74 \mathrm{ab}$ \\
Jarak $(0,1 \%)$ & $21,80 \pm 2,83 \mathrm{ab}$ \\
Cengkeh $(0,05 \%)$ & $21,48 \pm 2,98 \mathrm{ab}$ \\
Cengkeh $(0,1 \%)$ & $24,26 \pm 1,85 \mathrm{ab}$ \\
Serai $(0,05 \%)$ & $17,60 \pm 5,23 \mathrm{ab}$ \\
Serai $(0,1 \%)$ & $20,77 \pm 3,01 \mathrm{ab}$ \\
Mimba $(0,05 \%)$ & $14,28 \pm 1,81 \mathrm{ab}$ \\
Mimba $(0,1 \%)$ & $13,27 \pm 1,21 \mathrm{a}$ \\
Kontrol & $25,53 \pm 4,15 \mathrm{~b}$ \\
\hline
\end{tabular}

Keterangan : X: rata-rata, SE: Standar eror. Angka yang diikuti huruf yang sama tidak berbeda nyata menurut uji Duncan pada taraf nyata $5 \%$.

Tabel 3. Pengaruh perlakuan minyak nabati terhadap lama perkembangan larva S. frugiperda

\begin{tabular}{llrrrrrrr}
\hline Perlakuan & \multicolumn{7}{c}{ X \pm SE (Hari) } \\
\cline { 2 - 8 } & $\mathrm{N}$ & \multicolumn{1}{c}{ Instar II-III } & $\mathrm{N}$ & \multicolumn{1}{c}{ Instar II-IV } & $\mathrm{N}$ & Instar II-V & $\mathrm{N}$ & \multicolumn{1}{l}{ Instar II-VI } \\
\hline Jarak (0,05\%) & 37 & $2,35 \pm 0,08$ & 35 & $4,57 \pm 0,11$ & 35 & $7,40 \pm 0,12$ & 35 & $10,43 \pm 0,08$ \\
Jarak (0,1\%) & 36 & $2,75 \pm 0,07$ & 29 & $4,72 \pm 0,16$ & 29 & $7,93 \pm 0,16$ & 29 & $10,76 \pm 0,12$ \\
Cengkeh (0,05\%) & 38 & $2,34 \pm 0,08$ & 34 & $4,62 \pm 0,13$ & 34 & $7,82 \pm 0,13$ & 34 & $10,56 \pm 0,08$ \\
Cengkeh (0,1\%) & 36 & $2,14 \pm 0,06$ & 30 & $4,70 \pm 0,14$ & 30 & $7,17 \pm 0,07$ & 30 & $10,33 \pm 0,09$ \\
Serai (0,05\%) & 38 & $2,89 \pm 0,05$ & 35 & $5,20 \pm 0,12$ & 35 & $7,46 \pm 0,08$ & 35 & $11,06 \pm 0,20$ \\
Serai (0,1\%) & 38 & $2,84 \pm 0,18$ & 30 & $4,73 \pm 0,11$ & 30 & $7,07 \pm 0,05$ & 30 & $10,30 \pm 0,08$ \\
Mimba (0,05\%) & 35 & $2,66 \pm 0,08$ & 32 & $5,81 \pm 0,18$ & 32 & $7,77 \pm 0,13$ & 32 & $11,58 \pm 0,13$ \\
Mimba (0,1\%) & 35 & $2,75 \pm 0,07$ & 23 & $5,65 \pm 0,35$ & 23 & $11,17 \pm 0,21$ & 23 & $13,30 \pm 0,25$ \\
Kontrol & 40 & $2,10 \pm 0,05$ & 40 & $4,05 \pm 0,03$ & 40 & $7,27 \pm 0,08$ & 40 & $10,57 \pm 0,08$ \\
\hline X:
\end{tabular}

X: rata-rata, SE: Standar eror

Tabel 4. Pengaruh perlakuan minyak nabati terhadap bobot Pupa S. frugiperda

Perlakuan

Jarak $(0,05 \%)$

Jarak $(0,1 \%)$

Cengkeh $(0,05 \%)$

Cengkeh $(0,1 \%)$

Serai $(0,05 \%)$

Serai $(0,1 \%)$

Mimba $(0,05 \%)$

Mimba $(0,1 \%)$

Kontrol

Keterangan : X: rata-rata, SE: Standar eror.

Angka yang diikuti huruf yang sama tidak berbeda nyata menurut uji Duncan pada taraf nyata $5 \%$.
Toksisitas Minyak Mimba terhadap S. frugiperda Mortalitas larva $S$. frugiperda terjadi mulai satu hari setelah perlakuan yang terutama terjadi pada konsentrasi tinggi dengan kecenderungan meningkat sejalan dengan waktu pengamatan dan mencapai puncaknya antara hari ke-7 hingga hari ke-9 setelah perlakuan. Mortalitas larva uji pada hari selanjutnya cenderung stabil (Gambar 1). Hal ini menunjukkan bahwa minyak biji mimba bekerja lambat dalam menyebabkan kematian larva serangga uji. 


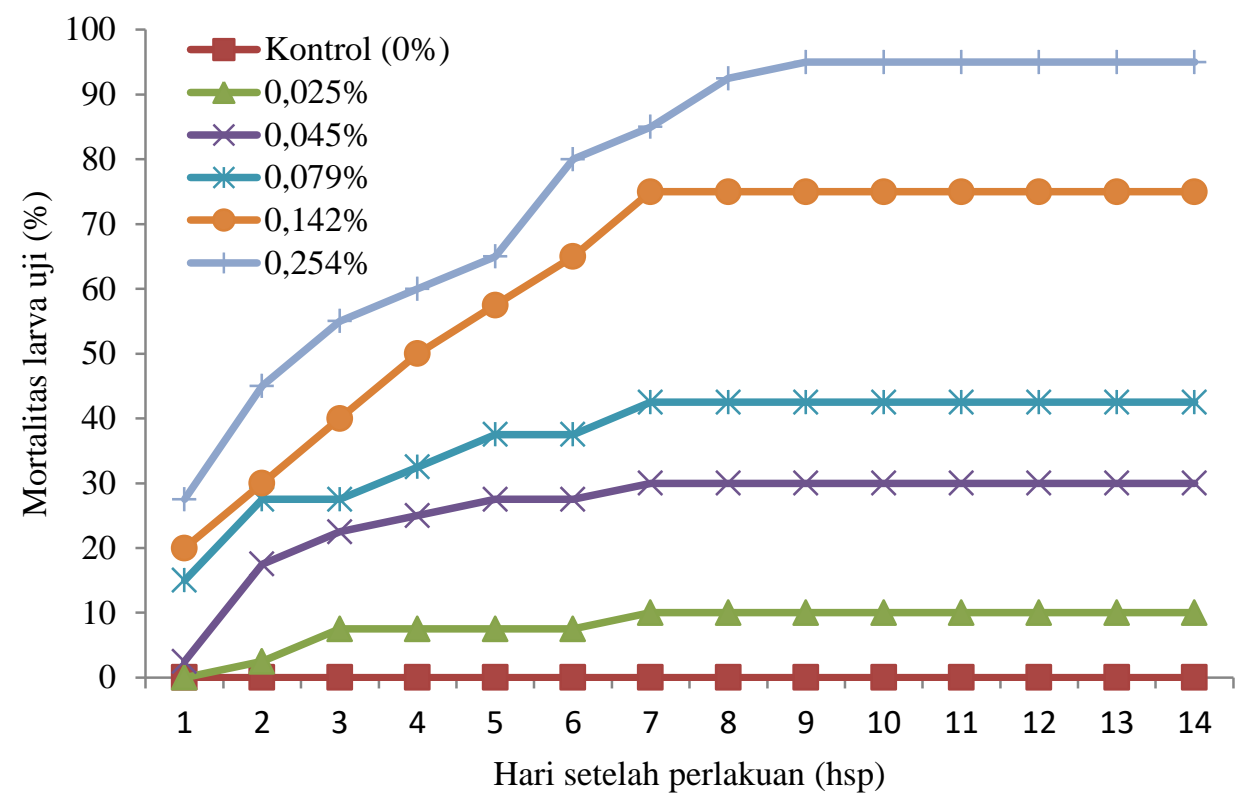

Gambar 1. Mortalitas larva S. frugiperda yang mendapat perlakuan minyak biji A. indica.

Larva serangga umumnya mengalami kematian pada fase perkembangan lebih lanjut dengan gejala kegagalan pergantian kutikula dan kegagalan melepaskan kapsul kepala. Larva serangga uji yang bertahan hidup menunjukkan indikasi pertumbuhan terhambat, bobot tubuh yang lebih rendah, waktu perkembangan yang lebih lama yang sejalan dengan percobaan sebelumnya (uji penapisan). Beberapa hasil penelitian melaporkan bahwa senyawa aktif dari dari biji $A$. indica memiliki aktivitas sebagai penghambat pertumbuhan, gangguan perkembangan, memperlama waktu perkembangan dan penghambat makan (Senthil-Nathan,2013; Dawkar et al., 2019; BezzarBendjazia et al., 2016). Mordue \& Blackwell (1993) dan Koul (1996) mengemukakan bahwa senyawa aktif azadirakhtin yang terkadung dalam minyak mimba mengakibatkan hambatan pelepasan protorasikotropik hormon (PTTH) dari kelenjar korpora kardiaca dan menghambat pelepasan ekdison dari brain ring glands complex (BRC's) sehingga mengakibatkan gangguan perkembangan pada serangga uji.

Hasil analisis probit hubungan konsentrasi minyak biji $A$. indica dengan mortalitas larva menunjukkan bahwa minyak biji $A$. indica memiliki toksisitas yang cukup kuat terhadap $S$. frugiperda dengan nilai dengan nilai $\mathrm{LC}_{50} 0,079 \%\left(\mathrm{SK}_{95} 0,066-\right.$ $0,095 \%)$ dan $\mathrm{LC}_{95}$ 0,338\% $\left(\mathrm{SK}_{95} 0,024-0,567 \%\right)$ pada hari ke-14 setelah perlakuan (Tabel 5.). Metabolit sekunder tanaman memiliki toksisitas yang kuat jika memiliki LC $_{50}$ kurang dari 1000 ppm (Meyer et al., 1982).

Tabel 5. Parameter regresi probit hubungan konsentrasi minyak biji A. indica dengan mortalitas larva uji $S$. frugiperda

\begin{tabular}{ccccccc}
\hline $\begin{array}{c}\text { Waktu } \\
\text { pengamatan }\end{array}$ & $a \pm$ SE & $b \pm$ SE & $\mathrm{LC}_{50}$ & $\mathrm{SK}_{95}$ & $\mathrm{LC}_{95}$ & $\mathrm{SK}_{95}$ \\
\hline $2 \mathrm{HSP}$ & $0,74 \pm 0,32$ & $2,36 \pm 0,31$ & 0,29 & $0,19-0,75$ & 4,58 & $1,38-93,57$ \\
4 HSP & $1,25 \pm 0,31$ & $1,54 \pm 0,29$ & 0,16 & $0,12-0,24$ & 1,81 & $0,79-10,34$ \\
6 HSP & $2,17 \pm 0,34$ & $2,17 \pm 0,30$ & 0,10 & $0,08-0,13$ & 0,58 & $0,37-1,22$ \\
8 HSP & $2,87 \pm 0,38$ & $2,61 \pm 0,33$ & 0,08 & $0,07-0,10$ & 0,34 & $0,24-0,57$ \\
$10 \mathrm{HSP}$ & $2,87 \pm 0,38$ & $2,61 \pm 0,33$ & 0,08 & $0,07-0,10$ & 0,34 & $0,02-0,57$ \\
12 HSP & $2,87 \pm 0,38$ & $2,61 \pm 0,33$ & 0,08 & $0,07-0,10$ & 0,34 & $0,02-0,57$ \\
14 HSP & $2,87 \pm 0,38$ & $2,61 \pm 0,33$ & 0,08 & $0,07-0,10$ & 0,34 & $0,02-0,57$ \\
\hline
\end{tabular}

Keterangan : $a$ : intersep garis regresi, $b$ : kemiringan garis regresi (Slope), SE: Standar Eror

LC: Letal concentration, SK : Selang kepercayaan

\section{KESIMPULAN}

Mortalitas tertinggi larva S. frugiperda hasil uji penapisan ditunjukkan oleh perlakuan minyak biji mimba dibanding dengan minyak nabati lainnya. Pada konsentrasi $0,1 \%$, minyak biji mimba dapat memperpanjang lama waktu perkembangan larva, menurunkan konsumsi pakan larva, dan bobot pupa $S$. frugiperda. Minyak biji mimba memiliki toksisitas yang kuat terhadap larva $S$. frugiperda dengan nilai $\mathrm{LC}_{50} 0,08 \%$ (SK (95\%) 0,07-0,10\%) dan $\mathrm{LC}_{95}$ $0,34 \%$ (SK (95\%) 0,02-0,57\%). 


\section{DAFTAR PUSTAKA}

Abrahams P., Beale T., Cock M., CornianiN., Day R., Godwin J., Murphy S., Richards G. \& Vos J. 2017. Fall Armyworm Status. Impacts and control options in Africa: Preliminary Evidence Note. 14p. The UK's Department for International Development (DFID).

Ahadian F, Ginting N, Wahyuni TH, \& Anwar. 2012. Efektivitas skabisida ekstrak daun mimba (Azadirachta indica A. Juss) terhadap tungau Sarcoptes scabiei in vitro. J. Peternakan Integratif. 1(1): 1-10.

Ajayi OE, Oladipupo SO, \& Ojo TB. 2018. The Fumigant Toxicity of Syzygium aromaticum and Cymbopogon citratus Oils on Selected Life Stages of Tribolium castaneum (Coleoptera: Tenebrionidae). Jordan Journal of Biological Sciences. 11(20): $571-575$.

Aliah N, Susiawaty A, \& Ibrahim IA. 2016. Uji efektivitas ekstrak daun cengkeh (Syzigium Aromaticum) sebagai repellent semprot terhadap lalat rumah (Musca Domestica). Higiene. 2(3):113-120.

Arivoli S, \& Tennyson S. 2013. Antifeedant activity, development indices and morphogenetic variation of plant extracts against Spodoptera litura (Fab.) (Lepidoptera : Noctuidae). Journal of Entomology and Zoology Studies, 1(4), 87-96. Retrieved from http://www.entomoljournal.com/vol1Issue4/I ssue_aug_2013/25.1.pdf.

Astuthi, MMM, Sumiarta K, Susila IW, Wirya GHAS, \& Sudiarta IP. 2012. Efikasi minyak atsiri tanaman cengkeh (Syzygium aromaticum (L.) Meer. \& Perry), pala (Myristica fragrans Houtt), dan jahe (Zingiber officinale Rosc.) terhadap mortalitas ulat bulu gempinis dari famili lymantriidae. J. Agric. Sci. and Biotechnol. 1(1): 12-23.

Bakr RFA, Al Yousef Al BF, \& Hassan SH. 2015. Toxicological effect of the botanical extract castor oil seeds Ricinus communis and their biochemical activity on the cotton leafworm, Spodoptera littoralis (Boisd.) (Lepidoptera: Noctuidae). Egypt. Acad. J. Biolog. Sci. 7(1): $99-111$.

Bezzar-Bendjazia R, Kilani-Morakchi S, Aribi N. 2016. Growth and molting disruption effects of azadirachtin against Drosophila melanogaster (Diptera: Drosophilidae). JEZS 2016; 4(1): 363-368.

Dawkar VV, Barage SH, Barbole RS, Fatangare A, Grimalt S, Haldar S, Heckel DG, Gupta VS, Thulasiram HV, Svatoš A, \& Giri AP. 2019. Azadirachtin-A from Azadirachta indica impacts multiple biological targets in Cotton Bollworm Helicoverpa armigera. ACS
Omega 2019, 4, 9531-9541. DOI: 10.1021/acsomega.8b03479.

De Almeida SR, de Souza ARW, Vieira SMJ, de Oliveira HG, Holtz AM. 2002. Biology review, occurrence and control of Spodoptera frugiperda (Lepidoptera: Noctuidae) in corn in Brazil. Biosci. J. 18: 41-48.

Faheem F \& Abduraheem K. 2019. Repellent activity of Nigella sativa, Syzygium aromaticum and Azadirachta indica essential oils against the skin and skin product pest (Anthrenus verbasci) in Museums. Journal of Innovations in Pharmaceutical and Biological Sciences (JIPBS). 6(4): 57-69.

Food and Agricultural Organization (FAO). 2019. Indonesia prepares for battle with Fall Armyworm.

http://www.fao.org/indonesia/news/detailevents/en/c/1202177/. Accessed on January 2020.

Finney, D. J. 1971. Probit Analysis, 3rd ed. Cambridge University Press, Cambridge, England.

Ganjewala D. 2009. Cymbogon essential oils: Chemical compositions and bioactivites. International Journal of Essential Oil Therapeutics. 3: 56-65.

Goergen G, Kumar PL, Sankung SB, Togola A, Tamò M. 2016.First report of outbreaks of the fall armyworm Spodoptera frugiperda (JE Smith) (Lepidoptera: Noctuidae), a new alien invasive pest in West and Central Africa. Plos

One.|

Doi:10.1371/journal.pone.0165632.

Hernandez-Lambrano R, Pajaro-Castro N, CaballeroGallardo K, Stashenko K, \& Olivero-Verbel J. 2015. Essential oils from plants of the genus Cymbopogon as natural insecticides to control stored product pests. Journal of Stored Products Research. 62: 81-83.

Ibrahim RA \& Alahmadi SS. 2015. Effect of Syzygium aromaticum cloves on larvae of the rhinoceros beetle. Oryctes agamemnon (Coleoptera: Scarabaeidae). African Entomolog. 23(2): 458-466.

Johnson SJ. 1987. Migration and life history strategy of the fall armyworm, Spodoptera frugiperda in the Western Hemisphere. International Journal of Tropical Insect Science. 8: 543549. DOI: 10.1017/S1742758400022591.

Kodjo TA, Gbénonchi M, Sadate A, Komi A, Yaovi G Dieudonné M, \& Komla S. 2011. Bioinsecticidal effects of plant extracts and oil emulsions of Ricinus communis L. (Malpighiales: Euphorbiaceae) on the diamondback, Plutella xylostella L. (Lepidoptera: Plutellidae) under laboratory and semi-field conditions. Journal of Applied Biosciences. 43: $2899-2914$. 
Koul O. 1996 Mode of action of azadirachtin in insect. In Neem. NS Randhawa and BS Parmar (eds). Pp. 160-170. New Age International (P)LTD. New Delhi.

Labinas MA \& Crocomo WB. 2002. Effect of java grass (Cymbopogon winterianus) essential oil on fall armyworm Spodoptera frugiperda (J. E. Smith, 1979) (Lepidoptera, Noctuidae). Acta Scientiarum. 24(5): 1401-1405.

Maharani Y, Dewi VK, Puspasari LT, Rizkie L, Hidayat Y, Dono D. 2019.Cases of Fall Army Worm Spodoptera frugiperda J. E. Smith (Lepidoptera: Noctuidae) Attack on Maize in Bandung, Garut and Sumedang District, West Java. Jurnal Cropsaver 2019. 2(1): 38-46.

Manurung R, Chahaya I \& Dharma S. 2013. Pengaruh tolak perasan serai wangi (Cymbopogon nardus) terhadap gigitan nyamuk Aedes aegypti. Lingkungan dan kesehatan kerja. 2(1): 1-11.

Mardiningsih TL, Sukmana C, Tarigan N, \& Suriati S. 2010. Efektivitas insektisida nabati berbahan aktif azadirachtin dan saponin terhadap mortalitas dan intensitas serangan Aphis gossypii Glover. Bul. Littro. 21(2): $171-$ 183.

Meyer, B.N., Ferrigni, N.R., Putnam, J.E.,Jacobsen, L.B., Nicholas, D.E., and McLaughlin, J.L. (1982). Brine Shrimp : a Convenient General Bioassay for ActivePlant Constituents. Journal of Medicinal Plant Research. 45:3134. doi: 10.1055/s-2007-971236.

Mishra B, Tripathi SP, \& Tripathi CPM. 2016. Impact of Syzygium aromaticum (L.) essential oil as fumigant against Tribolium castaneum (Coleoptera: Tenebrionidae). Journal of Entomology and Zoology Studies. 4(6): 811816.

Mordue (Luntz) AJ, \& Blackwell A.1993. Azadirachtin: an update. Journal of Insect Physiology. 39(11): 903-924. https://doi.org/10.1016/00221910(93)90001-8.

Paul D, \& Sohkhlet MD. 2012. Anti-feedant, repellent and growth regulatory effects of four plant extracts on Pieris brassicae larvae (Lepidoptera: Pieridae). Open Access Scientific Reports. 1(10), 485. Retrieved from https://www.omicsonline.org/scientificreports/2155-6202-SR-485.pdf.

Pebriansyah R, Yasin N, Subeki \& Sudarsono H. 2016. Toksisitas ekstrak biji jarak pagar (Jatropha curcas L.) terhadap ulat krop kubis (Crocidolomia pavonana F.). J. Agrotek Tropika. 4(3): $211-216$.

Pinheiro PF, de Queiroz VT, Rondelli VM, Costa AV, Marcelino TdeP, \& Pratissoli D. 2013.

Insecticidal Activity Of Citronella Grass Essential Oil On Frankliniella schultzei and
Myzus persicae. Ciênc. agrotec., Lavras, 37

(2): 138-144.

Puji EA, Riyadhi A, \& Roufiq NA. 2011. Efektivitas minyak jarak pagar sebagai larvasida, antioviposisi dan ovisida terhadap larva nyamuk Aedes albopictus. Bull. Littro. 22 (1): 44-53.

Ramos V, Alves D, Braga M, Carvalho G, \& Santos C. 2013. Extraction and isolation of antitryptic castor-bean (Ricinus communisL.) substances and their effects on Spodoptera frugiperda (Smith, 1797) (Lepidoptera: Noctuidae). Chilean Journal Of Agricultural Research. 73(2): 128-134.

Rohimatun \& Laba IW. 2013. Efektivitas insektisida minyak serai wangi dan cengkeh terhadap hama pengisap buah lada (Dasynus piperis China). Bul. Littro. 24 (1): 26-34.

Samsudin. 2011. Biosintesa dan cara kerja azadirachtin sebagai bahan aktif insektisida nabati. Semnas Pesnab IV Jakarta 15 Oktober 2011.

Setiawati W, Murtaningsih R, \& Hasyim A. 2011. Laboratory and field evaluation of essential oils from Cymbopogon nardus as oviposition deterrent and ovicidal activities against Helicoverpa armigera Hubner on chili pepper. Indonesian Journal of Agricultural Science. 12(1): 9-16.

Senthil-Nathan S. 2013 . Physiological and biochemical effect of neem and other Meliaceae plants secondary metabolites against Lepidopteraninsects. Frontiers in Physiology. doi: 10.3389/fphys.2013.00359.

Shannag HK, Capinera JL, \& Freihat NM. 2015. Effects of Neem-Based Insecticides on Consumption and Utilization of Food in Larvae of Spodoptera eridania (Lepidoptera: Noctuidae). J. Insect Sci. (2015) 15(1): 152: DOI: $10.1093 /$ jisesa/iev134.

Syahputra E, Prijono D, Dadang, Manuwoto S, \& Darusman LK. 2006. Respons fisiologi Crocidolomia pavonana terhadap fraksi aktif Calophyllum soulattri. Hayati: Journal of Biosciences. $13(1)$ : 7-12. https://doi.org/10.1016/S19783019(16)30372-2.

Syahputra E., Hernowo K, \& Riko, 2019. Effect of Castanopsis megacarpa Extract on Mortality, Longevity Development and Feeding of Crocidolomia pavonana Larvae. Agrivita Journal of Agricultural Science. 41(3): 537543.

Trisyono YA, Suputa, Aryuwandari VEF, Hartaman M, \& Jumari. 2019. Occurrence of Heavy Infestation by the Fall Armyworm Spodoptera frugiperda, a New Alien Invasive Pest, in Corn in Lampung Indonesia. Jurnal Perlindungan Tanaman Indonesia. $\quad 23(1)$ : 156-160. https://doi.org/10.22146/jpti.46455. 
Wamaket N, Dieng $\mathrm{H}$, Komalamisra N, Apiwathnasorn C, Morales RE, Thanomsub BW, Srisawat R, \& Attrapadung S. 2018. Larvicidal and adulticidal activities of castor oil against the dengue vector, Aedes aegypti. Tropical Biomedicine. 35(3): 610-618.

Widayani NS, Haq AN, Puspasari LT, Hidayat Y, Dono D. 2018. Effect of temperature, storage time, the residual test of neem oil formulation (Azadirachta indica A. Juss) and bitung formulation (Baringtonia asiatica) to its toxicity against large cabbage heart caterpillar (Crocidolomia pavonana F). Jurnal Cropsaver. 1(1): 27-36.

Zapata N, Budia F, Viñuela E, \& Medina P. 2009. Antifeedant and growth inhibitory effects of extracts and drimanes of Drimys winteri stem bark against Spodoptera littoralis (Lepidoptera: Noctuidae). Industrial Crops and Products. 30(1): 119-125. https://doi.org/10.1016/j.indcrop.2009.02.00 9. 